\title{
Effects of Sulfur, Iron and Manganese Starvation on Growth, $\beta$-carotene Production and Lipid Profile of Dunaliella salina
}

\author{
Saeedeh Shaker ${ }^{1}$, Mohammad Hossein Morowvat ${ }^{1}$, , Younes Ghasemi ${ }^{1}$ 2* $^{*}$ \\ ${ }^{1}$ Pharmaceutical Sciences Research Center, School of Pharmacy, Shiraz University of Medical Sciences, P.O. Box 71345-1583, Shiraz, IRAN. \\ 2Department of Pharmaceutical Biotechnology, School of Pharmacy, Shiraz University of Medical Sciences, P.O. Box 71468-64685, Shiraz, IRAN.
}

\begin{abstract}
Objective: Microalgal pharmaceutical biotechnology is mainly dependent on the biomass yield and also the final concentration of the obtained lipids. $\beta$-carotene is one of the most precious nutraceuticals, of both preventive and therapeutics importance in pharmacy and medicine. Dunaliella salina is known as famous $\beta$-carotene producer which could accumulate the $\beta$-carotene up to $10 \%$ of its dry cell weights. The amount of different macro and micronutrients in $D$. salina culture medium defines its productivity and $\beta$-carotene content. Methods: In this study, the effects of sulfur, iron and manganese deprivation, on cell growth and $\beta$-carotene biosynthesis in a naturally isolated strain of $D$. salina was examined. Besides, the fatty acid profile of the naturally isolated strain was also investigated. Results: Sulfur, iron and manganese deprivation caused a noticeable decrease in the cell growth of $D$. salina. On the other hand, in nutrient depleted media, the maximum $\beta$-carotene concentration was significantly improved $(14.616 \mathrm{mg}$ $\mathrm{L}-1$ in sulfur starvation, $14.994 \mathrm{mg} \mathrm{L-1}$ in iron starvation and $10.119 \mathrm{mg} \mathrm{L-1}$ in manganese starvation media) compared with initial values (6.753 mg L-1) in basic culture medium. The obtained fatty acids from the studied microalgal strain found to be some important saturated, monounsaturated and polyunsaturated fatty acids. Conclusion: Owing to its significant growth
\end{abstract}

rate, $\beta$-carotene contents and fatty acid profile; the naturally isolated microalgal strain could be exploited as a potential producer strain. Besides, the nutrient limitation strategy could be effectively employed to improve the $\beta$-carotene production procedure in $D$. salina.

Key words: Nutrient starvation, Dunaliella salina, $\beta$-carotene production, Fatty acid profile, Nutraceuticals

Correspondence :

M. H. Morowvat,

Pharm. D., Ph. D. in Pharmaceutical Biotechnology, Assistant Professor, Pharmaceutical Sciences Research Center, School of Pharmacy, Shiraz University of Medical Sciences, P.O.Box:71345/1583, Shiraz, IRAN.

Tel \& Fax: +98-71 324267 29; Cell Phone: +98-936 3249640

E-mail:mhmorowvat@sums.ac.ir

Personal website: http://www.mhmorowvat.com

Academic website: http://www.sums.ac.ir

DOI: 10.5530/jyp.2017.9.9

\section{INTRODUCTION}

The halotolerant unicellular microalga Dunaliella salina has been known as considerable natural source of the antioxidants, $\beta$-carotene, and the lipophilic high-value compound. ${ }^{1}$ Carotenoids have been used in various body-cares, cosmetic and pharmaceutical products. ${ }^{2,3}$ The therapeutic applications of $\beta$-carotene such as preventive agent in anti-cancer therapy regimes are considerable because of its fascinating protective potential against oxygen free radicals. ${ }^{4}$ Moreover, it has been commercialized as food additives including vitamins and antioxidants. ${ }^{5}$ Under appropriate growth conditions, the growth trends of microalgal cells and $\beta$-carotene production continue normally, but some inappropriate environmental conditions, such as increased light intensity, ${ }^{6}$ high salt concentrations, ${ }^{7,8}$ nitrogen starvation, ${ }^{9}$ higher temperatures ${ }^{10}$ and more importantly, different nutrients limitation, ${ }^{11,12}$ cause biochemical and morphological changes in the microalgal cells. Having a dynamic cell physiology, D. salina cells, show a persistent strategy, and tend to accumulate lipids, pigments and $\beta$-carotene in this nutrient depletion conditions. ${ }^{13}$

Culture medium determines the nutritional and chemical environment of microorganisms during cultivation. ${ }^{14}$ Hence, investigation regarding the physiologic and metabolic changes in the microalgal cells, their growth pattern and also their composition during nutrient limitation in culture medium is of importance. The obtained data could be employed to increase the growth rates and also improve the $\beta$-carotene production process.
Some researchers have reported effects of nitrogen starvation on cell physiology, $\beta$-carotene and fatty acid metabolism. ${ }^{12,15}$ Nevertheless, sulfur, iron and manganese are considered as major macro- and micronutrients which play a critical role during $\beta$-carotene biosynthesis in different metabolic pathways. Also their exact contribution in D. salina growth and $\beta$-carotene process has not been studied yet.

Sulfur is regarded as an essential parameter which plays a critical role in the electron transport chain, lipid metabolism and also protein biosynthesis. ${ }^{16}$ It has been proven that sulfate limitation decreases the cell volume, growth rates and also the photosynthetic activity. Nevertheless, the chlorophyll and protein levels remained unchanged. ${ }^{17}$ On the other hand, the sulfate deprivation, might cause an elevation in the total pigment content in D. salina. ${ }^{18}$ Iron is an essential required factor for most living organisms and also is known as a cofactor in main cellular processes such as DNA biosynthesis, photosynthesis and respiration. ${ }^{19}$ Efficacy of adding the mineral composition such as iron to the basic growth medium, was also investigated. ${ }^{20}$ Furthermore, manganese as a micronutrient can significantly impact the cellular metabolism in Dunaliella tertiolecta. ${ }^{21}$ Although, manganese deprivation has not changed significantly the lipid content in D. tertiolecta cells. ${ }^{11}$ But, it is quite worthy to study its impacts on growth rate and $\beta$-carotene production in D. salina.

This study explores the effects of sulfur, iron and manganese starvation, on growth and $\beta$-carotene biosynthesis in a naturally isolated strain of D. salina. The results were compared to the basic culture conditions. Besides, the fatty acid profile of the naturally isolated strain was also

This is an open access article distributed under the terms of the Creative Commons Attribution-NonCommercial-ShareAlike 4.0 License, which allows others to remix, tweak, and build upon the work non-commercially, as long as the author is credited and the new creations are licensed under the identical terms. 


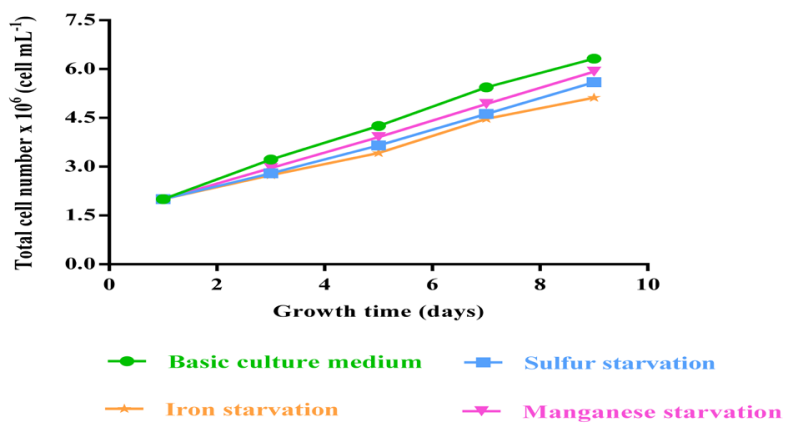

Figure 1: Effect of sulfur, iron and manganese nutrient deficiency on growth trend of D. salina during 10 days of starvation experiment.

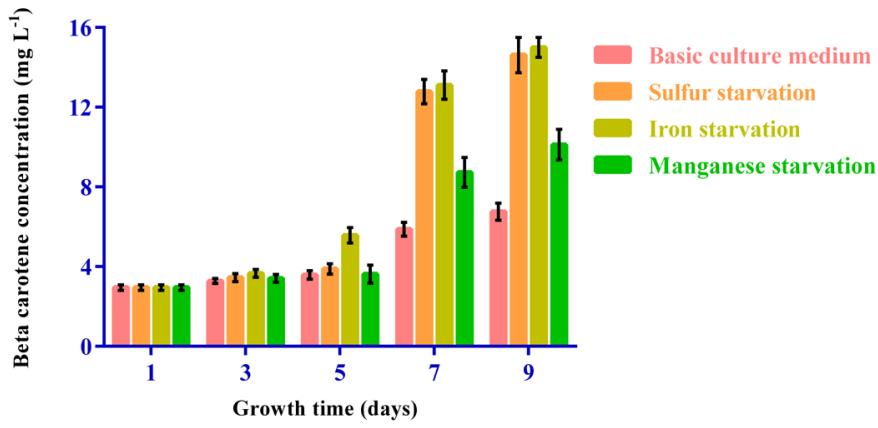

Figure 2: Effect of sulfur, iron and manganese nutrient deficiency on $\beta$-carotene concentration ( $\mathrm{mg} \mathrm{L}-1$ ) in D. salina during 10 days of starvation experiment. The presented data are the mean values for three different experiments with error bars.

Table 1: Effects of three distinct nutrient depletion media on the final $\beta$-carotene concentration $\left(\mathrm{mg} \mathrm{L}^{-1}\right)$ in $D$. salina culture

\begin{tabular}{|c|c|c|c|c|c|}
\hline \multirow[b]{2}{*}{ Growth time (days) } & \multicolumn{5}{|c|}{$\beta$-carotene concentration $\left(\mathrm{mg} \mathrm{L}^{-1}\right)$} \\
\hline & 1 & 3 & 5 & 7 & 9 \\
\hline Basic culture medium & 2.948 & 3.279 & 3.578 & 5.871 & 6.753 \\
\hline Sulfur starvation & 2.948 & 3.442 & 3.880 & 12.776 & 14.616 \\
\hline Iron starvation & 2.948 & 3.654 & 5.569 & 13.104 & 14.994 \\
\hline Manganese starvation & 2.948 & 3.411 & 3.616 & 8.723 & 10.119 \\
\hline
\end{tabular}

Table 2: Fatty acid composition of Dunaliella salina with IUPAC and common names, formula and family type

\begin{tabular}{cccc}
\hline IUPAC name & Common name & Formula & Type \\
\hline Hexanoic acid & Caproic acid & $\mathrm{C}_{6} \mathrm{H}_{12} \mathrm{O}_{2}$ & SFA \\
3-Hexenoic acid & & $\mathrm{C}_{6} \mathrm{H}_{10} \mathrm{O}_{2}$ & MUFA \\
Octanoic acid & Caprylic acid & $\mathrm{C}_{8} \mathrm{H}_{16} \mathrm{O}_{2}$ & SFA \\
Methyl decanoate & Methyl caprinate & $\mathrm{C}_{11} \mathrm{H}_{22} \mathrm{O}_{2}$ & FAME \\
Dodecanoic acid & Lauric acid & $\mathrm{C}_{12} \mathrm{H}_{24} \mathrm{O}_{2}$ & SFA \\
Tetradecanoic acid & Myristic acid & $\mathrm{C}_{14} \mathrm{H}_{28} \mathrm{O}_{2}$ & SFA \\
Methyl tetradecanoate & & $\mathrm{C}_{15} \mathrm{H}_{30} \mathrm{O}_{2}$ & FAME \\
Octadecanoic acid & Stearic acid & $\mathrm{C}_{18} \mathrm{H}_{36} \mathrm{O}_{2}$ & SFA \\
6-Octadecenoic acid & Petroselinic acid & $\mathrm{C}_{18} \mathrm{H}_{34} \mathrm{O}_{2}$ & MUFA \\
9,12-Octadecadienoic acid & Linoleic acid & $\mathrm{C}_{18} \mathrm{H}_{32} \mathrm{O}_{2}$ & PUFA \\
Tetracosanoic acid & Lignoceric acid & $\mathrm{C}_{24} \mathrm{H}_{48} \mathrm{O}_{2}$ & SFA \\
\hline
\end{tabular}

"SFA = saturated fatty acid, MUFA = mono unsaturated fatty acid, PUFA = poly unsaturated fatty acid, FAME = fatty acid methyl ester.

determined to assess its potential to be employed as an industrial biodiesel producer.

\section{MATERIALS AND METHODS}

\section{Algal source and culture conditions}

The microalga Dunaliella salina was isolated from the Maharlu Salt Lake located in southeast of Shiraz, Fars province, Iran. The samples of microalgae were collected in sterile bottles and then were transferred to the laboratory. The isolated unialgal culture was gained by sub culturing the alga in a fresh Johnson medium ( $\mathrm{pH} 7.5)$ with $12 \%$ salinity. ${ }^{22}$ Moreover, the microscopic analysis and identification of the cells were done on colonies grown on solid Johnson medium using previously described methods. ${ }^{23}$ The ribosomal $18 \mathrm{~S}$ rRNA gene sequencing using PCR method was accomplished using single cell taken directly from plates. The exploited PCR protocol for amplification of the ribosomal genes has been described elsewhere. ${ }^{24}$ After several stages of sub culturing, the samples were cultivated in Erlenmeyer flasks $(250 \mathrm{~mL})$ containing $100 \mathrm{~mL}$ of Johnson medium at $25 \pm 2{ }^{\circ} \mathrm{C}$ under $16: 8 \mathrm{~h}$ (light/dark cycle) with white fluorescent light at $52.84 \mathrm{~mol} \mathrm{~m}^{-2} \mathrm{~s}^{-1}$ light intensity and shaking at $130 \mathrm{rpm}$ for 10 days.

After the $10^{\text {th }}$ day of growth phase, the cultures were harvested and maintained as control cells and also used as inoculums for stress-phase cultivation for another 10 days of cultivation. Three main stress conditions (Sulfur (S), iron (Fe) and manganese ( $\mathrm{Mn}$ ) depleted) were tested to identify the effects of stress condition on total $\beta$-carotene concentration in D. salina. 
After $10^{\text {th }}$ day of cultivation, the initial cultures, were used to set-up the stress experiments. The microalgal cells were carefully separated by centrifugation at $3000 \times g, 20^{\circ} \mathrm{C}$ for $5 \mathrm{~min}$ and the obtained pellets were washed twice before final resuspension in suitable stress medium. Stress experiments were performed in triplicate in $250 \mathrm{~mL}$ Erlenmeyer flasks containing $90 \mathrm{~mL}$ of the specific stress medium (S, Fe and Mn depleted) and $10 \mathrm{~mL}$ of microalgae cells re-suspended in stock stress medium. The initial cells of microalgae were $4 \times 10^{5}$ cells $\mathrm{mL}^{-1}$.

\section{Cell counting}

Neubauer hemocytometer was used for cell quantitation with a $1 \% \mathrm{~mm}$ deep counting chamber by means of an electronic microscope with magnification $\times 40$ (Ceti microscope, Medline Scientific, UK). The microalgal cells were fixed using formaldehyde solution (10\%) before the counting procedure.

\section{Analytical methods}

The initial pigments of $\beta$-carotene were evaluated after 10 days of cultivation (mid stationary phase). $\beta$-carotene extraction from the microalgal cell pellets was performed using a mixture of ethanol/n-hexane $(2: 1, \mathrm{v} / \mathrm{v})$. $\mathrm{UV} /$ vis spectrophotometry method at $450 \mathrm{~nm}$ absorbance was used for detection of $\beta$-carotene content. ${ }^{22,25}$ Total lipid content was extracted and quantified using gravimetric method, ${ }^{5}$ using a mixture of methanol/ dichloromethane $(2: 1, \mathrm{v} / \mathrm{v}) .^{22}$ The lipid extraction procedure was repeated for three times. Fatty acid composition analysis was conducted as described before. ${ }^{26}$

\section{Statistical analysis}

The significant differences of mean $\beta$-carotene $(n=3)$ was evaluated by using ANOVA with statistically difference at a level of 5\%. IBM SPSS software version 22.0 (Armonk, NY: IBM Corp.) and Graph Pad prism version 6.00 (GraphPad Software, La Jolla California, USA) were used for statistical analysis.

\section{RESULTS AND DISCUSSION}

\section{Cell growth characteristics of D. salina}

The growth pattern of the studied microalgal strain was monitored during 10 days of cultivation after nutrient depletion experiment. The sampling was performed every three days and the results were depicted in Figure 1. During the first days of cultivation, the microalgal cells showed a lag phase during the first 3 days and maintained the exponential phase from day 3 to day 10, and then the growth rate remained at the stationary phase. The initial cells of microalga were reported as $4 \times 10^{5}$ cells $\mathrm{mL}^{-1}$. After 10 days of initial cultivation experiment, the microalgal cell number were reached up to $2 \times 10^{6}$ cell $\mathrm{mL}^{-1}$. After beginning the starvation study, with addition of the fresh medium, the cell growth was increase in a typical sigmoidal trends in all studied cultivation media. Nevertheless, the basic culture medium showed higher slopes compared with three other starved media. During another 10 days of nutrient depleted cultivation, trends of cell growth in the nutrient rich sample was higher than sulfur, iron and manganese deficient conditions. The maximum cell number of $6.32 \times 10^{6} \mathrm{cell} \mathrm{mL}^{-1}$ was obtained during 10 days of cultivation in nutrient rich medium. In $\mathrm{S}$ starved medium, a maximum amount of $5.60 \times 10^{6}$ cell $\mathrm{mL}^{-1}$ was detected. The highest cell number of $5.12 \times 10^{6} \mathrm{cell} \mathrm{mL}^{-1}$ was observed in Fe starved medium as well. Without Mn, only $5.92 \times 10^{6}$ cell $\mathrm{mL}^{-1}$ were obtained after 10 days of cultivation. The nutrient limited culture media gradually decreased possibly due to nutrient limitation in the culture medium. As the results indicate, Fe starvation caused more reduction $(81.01 \%)$ in cell numbers compared to $S(88.61 \%)$ and Mn (93.67\%) deprivation experiments compared to the control nutrient rich condition. The observed growth reduction in nutrient deprived media might be attributed to the unflavored growth conditions caused by limited nutrient concentrations in the culture medium. The lowest reduction values for cell growth was observed in Mn starvation which implies its lower contribution as a micronutrient in cell growth of D. salina compared with two studied macronutrients ( $\mathrm{S}$ and $\mathrm{Fe}$ ). The results of three distinct micro and macronutrient limitation on D. salina growth, were in agreement with the available data concerning the effects of nitrogen, sulfur and iron depletion on Dunaliella and other related microalgal strains..$^{12,27,28}$

\section{$\beta$-carotene content of $D$. salina}

The changes in $\beta$-carotene contents during complete $\mathrm{S}, \mathrm{Fe}$ and $\mathrm{Mn}$ depleted cultivation studies carried out in 10 days of study are provided in Figure 2. The presented data are the mean values for three different experiments with error bars. The $\beta$-carotene content was elevated from $6.753 \mathrm{mg} \mathrm{L}^{-1}$ in basic nutrient rich medium to $14.616 \mathrm{mg}^{\mathrm{L}-1}$ in S, 14.994 $\mathrm{mg} \mathrm{L}^{-1}$ in Fe starvation and $10.119 \mathrm{mg} \mathrm{L}^{-1}$ in $\mathrm{Mn}$ starvation culture media, respectively. On the other word, the nutrient starvation strategy improved the $\beta$-carotene production process in D. salina up to $216.44 \%$ (S starvation), 222.03\% (Fe starvation) and $149.84 \%$ (Mn starvation) compared with its initial values in nutrient rich medium. The presented data in Table 1 revealed that $\beta$-carotene production was increase in the stressful conditions caused by nutrient starvation. Based upon the results, it could be suggested that the availability of the major required elements for $D$. salina growth are inversely related to the $\beta$-carotene biosynthesis pathway. The similar observations have been reported by other researchers with $D$. salina, which accumulated more $\beta$-carotene content with lower nitrogen concentrations. ${ }^{12}$ Nevertheless, it has been indicated that increased $\beta$-carotene accumulation after reducing the nutrient concentrations in the culture medium is related to the species-specific reaction with a general trend. ${ }^{9}$ The $\beta$-carotene content in Dunaliella spp. is considered as a storage element or a singlet oxygen quencher. ${ }^{29}$ Several experiments have represented that some species of Dunaliella, under high irradiance conditions or cell division cycle while inflicted by environmental stress conditions, are able to accumulate more $\beta$-carotene levels. . $^{13,30}$

The present study demonstrates the effect of three nutrient depletions on the growth rate and chemical composition of the microalga. Nutrient deficient imposed on isolates of Dunaliella sp. showed an increase in $\beta$-carotene content. The maximum $\beta$-carotene content was observed $14.994 \mathrm{mg} \mathrm{mL}^{-1}$ in culture grown in iron deficient conditions (Table 2). Iron limitation conditions is postulated to prevent the cell division, so the rate of cells division became slow with decreased chlorophyll contents. ${ }^{31}$ Because of this, the cells of microalgae start to protect the cells against possible damage from radiation by producing more $\beta$-carotene. The same reaction were seen under sulfate and phosphate limiting conditions. ${ }^{9}$ The results demonstrated the possibility of using nutrient limitation strategy to maximize the $\beta$-carotene concentrations in the naturally isolated D. salina strain.

\section{Fatty acid composition analysis}

The fatty acid profile from the studied microalgal strain was inspected to evaluate its possibility for essential fatty acids and also biodiesel production purposes. The quantity and quality of the microalgal lipids is considered as a major factor to exploit the fatty acid methyl esters (FAMEs) from a microalga for alternative energy production. Normally, fatty acid methyl esters harboring 16-18 carbon atoms are considered suitable for biofuel production. ${ }^{32}$

Table 2 presents the identified fatty acids and fatty acid methyl esters identified in D. salina. Different fatty acid classes including saturated, mono unsaturated and poly unsaturated fatty acids ranging from 6 to 24 carbon atoms were detected. Hexanoic acid (caproic acid, 6:0), octanoic 
acid (caprylic acid, 8:0), Dodecanoic acid (Lauric acid, 12:0), tetradecanoic acid (myristic acid, 14:0), octadecanoic acid (stearic acid, 18:0) and tetracosanoic acid (lignoceric acid, 24:0) were identified as the main saturated fatty acids (SFA). Besides, some valuable types of monounsaturated fatty acids (MUFAs) such as 3-Hexenoic acid (6:1) and 6-Octadecadienoic acid (Petroselinic acid, 18:1) were also detected. The only identified polyunsaturated fatty acid (PUFA) were found to be 9, 12-Octadecadienoic acid (linoleic acid, 18:2) a poly unsaturated $\omega-6$ fatty acid. The major identifies FAMEs were also reported as methyl decanoate (11:0) and methyl tetradecanoate (15:0). The results of this study are in agreement with the presented results by other researchers performed in fatty acid profiling of $D$. salina..$^{33}$ As the results show, we detected some significant FAs/FAMEs with various pharmaceutical and nutritional applications. The observed FAs/FAMEs profile confirms the potential application of the identified strain for biodiesel production.

\section{CONCLUSION}

To sum up, sulfur, iron and manganese were confirmed as critical nutritional factors involving in cell growth, lipid production and $\beta$-carotene metabolism. Owing to its significant growth rate, $\beta$-carotene contents and fatty acid profile; the naturally isolated microalgal strain could be exploited as a potential producer strain in industrial scale. Nutrient depletion strategy as a bioprocess engineering method should be further examined in scale up or optimization studies

\section{ACKNOWLEDGEMENT}

This work was supported by Research Deputy of Shiraz University of Medical Sciences, Shiraz, Iran (Grant no. 94-01-36-9445).

\section{CONFLICT OF INTEREST}

The authors declare no conflict of interest.

\section{ABBREVIATIONS USED}

FA: Fatty acid; FAME: Fatty acid methyl ester; MUFA: Monounsaturated fatty acid; PUFA: Poly unsaturated fatty acid; SFA: Saturated fatty acid.

\section{REFERENCES}

1. Ghasemi $Y$, Rasoul-Amini S, Morowvat MH. Algae for the production of SCP. In: Liong MT, ed. Bioprocess Sciences and Technology: Nova Science Publishers, Inc.; 2011:163-84.

2. Ruiz-Núñez B, Schuitemaker GE, Dijck-Brouwer DAJ, Muskiet FAJ. Kinetics of plasma and erythrocyte-astaxanthin in healthy subjects following a single and maintenance oral dose. J Young Pharm. 2014;6(1):42-5

3. Lamers PP, Janssen M, De Vos RC, Bino RJ, Wijffels RH. Exploring and exploiting carotenoid accumulation in Dunaliella salina for cell-factory applications. Trends Biotechnol. 2008;26:631-38.

4. Ben-Amotz A, Avron M. The biotechnology of cultivating the halotolerant alga Dunaliella. Trends Biotechnol. 1990;8:121-26.

5. Metting Jr F. Biodiversity and application of microalgae. J Ind Microbiol. 1996; 17:477-89.

6. Hejazi M, Wijffels R. Effect of light intensity on $\beta$-carotene production and extraction by Dunaliella salina in two-phase bioreactors. Biomolecular Eng. 2003:20:171-5.

7. Fazeli M, Tofighi $H$, Samadi N, Jamalifar $H$. Effects of salinity on $\beta$-carotene production by Dunaliella tertiolecta DCCBC26 isolated from the Urmia salt lake, north of Iran. Bioresour Technol. 2006;97:2453-6.

8. Çelekli A, Dönmez G. Effect of pH, light intensity, salt and nitrogen concentrations on growth and $\beta$-carotene accumulation by a new isolate of Dunaliella sp.
World J Microbiol Biotechnol. 2006;22:183-9.

9. Phadwal K, Singh P. Effect of nutrient depletion on $\beta$-carotene and glycerol accumulation in two strains of Dunaliella sp. Bioresour Technol. 2003;90:55-8.

10. García F, Freile-Pelegrín Y, Robledo D. Physiological characterization of Dunaliella sp.(Chlorophyta, Volvocales) from Yucatan, Mexico. Bioresour Technol. 2007:98:1359-65.

11. Chen M, Tang H, Ma H, Holland TC, Ng KYS, Salley SO. Effect of nutrients on growth and lipid accumulation in the green algae Dunaliella tertiolecta. Bioresou Technol. 2011;102:1649-55.

12. Lamers PP, Janssen M, De Vos RCH, Bino RJ, Wijffels RH. Carotenoid and fatty acid metabolism in nitrogen-starved Dunaliella salina, a unicellular green microalga. J Biotechnol. 2012;162:21-7.

13. Gómez PI, González MA. The effect of temparature and irradiance on the growth and carotenogenic capacity of seven strains of Dunaliella salina (Chlorophyta) cultivated under laboratory conditions. Biol Res. 2005;38:151-62.

14. Morowvat $\mathrm{MH}$, Babaeipour $\mathrm{V}$, Memari HR, Vahidi H. Optimization of fermentation conditions for recombinant human interferon beta production by Escherichia coli using the response surface methodology. Jundishapur J Microbiol. 2015;8.

15. Kim SH, Liu KH, Lee SY, Hong SJ, Cho BK, Lee H, et al. Effects of light intensity and nitrogen starvation on glycerolipid, glycerophospholipid, and carotenoid composition in Dunaliella tertiolecta culture. PLoS ONE. 2013;8.

16. Hannon M, Gimpel J, Tran M, Rasala B, Mayfield S. Biofuels from algae: Challenges and potential. Biofuels. 2010;1:763-84.

17. Giordano M, Pezzoni V, Hell R. Strategies for the allocation of resources under sulfur limitation in the green alga Dunaliella salina. Plant Physiol. 2000;124:857-64.

18. Cao H, Zhang L, Melis A. Bioenergetic and metabolic processes for the survival of sulfur-deprived Dunaliella salina (Chlorophyta). J Appl Phycol. 2001;13:25-34.

19. Schwarz M, Sal-Man N, Zamir A, Pick U. A transferrin-like protein that does not bind iron is induced by iron deficiency in the alga Dunaliella salina. BBA-Proteins Proteom. 2003;1649:190-200.

20. Mojaat M, Pruvost J, Foucault A, Legrand J. Effect of organic carbon sources and $\mathrm{Fe} 2+$ ions on growth and $\beta$-carotene accumulation by Dunaliella salina. Biochem Eng J. 2008;39:177-84.

21. Chow $Y, T u W Y$, Wang D, Ng DHP, Lee YK. The role of micronutrients and strategies for optimized continual glycerol production from carbon dioxide by Dunaliella tertiolecta. Biotechnol Bioeng. 2015;112:2163-71.

22. Morowvat MH, Ghasemi Y. Culture medium optimization for enhanced $\beta$-carotene and biomass production by Dunaliella salina in mixotrophic culture. Biocatal Agr Biotechnol. 2016;7:217-23.

23. Ghasemi Y, Rasoul-Amini S, Morowvat MH, Azam SBM, Shokravi S, Mohagheghzadeh A, et al. Bioconversion of hydrocortisone by unicellular microalga Oocystis pusilla. Biotechnology. 2008;7:293-8.

24. Ghasemi Y, Rasoul-Amini S, Morowvat MH, Raee MJ, Ghoshoon MB, Nouri F, et al. Characterization of hydrocortisone biometabolites and 18S rRNA gene in Chlamydomonas reinhardtii cultures. Molecules. 2008;13:2416-25.

25. Eijckelhoff C, Dekker JP. A routine method to determine the chlorophyll a, pheophytin $a$ and $\beta$-carotene contents of isolated Photosystem II reaction center complexes. Photosynth Res. 1997;52:69-73.

26. Morowvat MH, Rasoul-Amini S, GhasemiY. Chlamydomonas as a "new" organism for biodiesel production. Bioresour Technol. 2010;101:2059-62.

27. Cakmak T, Angun P, Ozkan AD, Cakmak Z, Olmez TT, Tekinay T. Nitrogen and sulfur deprivation differentiate lipid accumulation targets of Chlamydomonas reinhardtii. Bioeng Bugs. 2012;3:343-6.

28. Menzyanova NG, Goltvyansky AV, Kuznetsova YA, Sysenko El. Season variability of iron effects on periodic culture of microalgae Dunaliella viridis Teod Front Biol China. 2009;4:328-36

29. Murthy KNC, Vanitha A, Rajesha J, Swamy MM, Sowmya PR, Ravishankar GA In vivo antioxidant activity of carotenoids from Dunaliella salina - a green microalga. Life Sci. 2005;76:1381-90.

30. Ben-Amotz A, Avron M. On the factors which determine massive $\beta$-carotene accumulation in the halotolerant alga Dunaliella bardawil. Plant Physiol. 1983;72:593-7.

31. Greene RM, Geider RJ, Kolber Z, Falkowski PG. Iron-induced changes in light harvesting and photochemical energy conversion processes in eukaryotic marine algae. Plant Physiol. 1992;100:565-75.

32. Huang G, Chen F, Wei D, Zhang X, Chen G. Biodiesel production by microalgal biotechnology. Appl Energ. 2010;87:38-46

33. Rasoul-Amini S, Ghasemi Y, Morowvat MH, Mohagheghzadeh A. PCR amplification of $18 \mathrm{~S}$ rRNA, single cell protein production and fatty acid evaluation of some naturally isolated microalgae. Food Chem. 2009;116:129-36. 